\section{P-215 THE SHAKESPEARE HOSPICE TRANSITIONAL CARE SERVICE INNOVATION IN PRACTICE}

Angie Arnold, Hazel Godwin. The Shakespeare Hospice, Stratford upon Avon, UK

\subsection{6/bmjspcare-2017-hospice. 240}

Background In 2014 a bespoke Young People's Hub was opened within our adult hospice setting to provide transitional care. This was the culmination of three years' preparatory work, including consultation with life-limited young people. This model of care is unique within the adult hospice setting and was recognised in 2016 by winning a prestigious national award from Glaxo Smith Kline in association with the King's Fund.

Aims The aim of the service is to provide a seamless transition for young people with life-limiting conditions aged between 16-24 years of age. The focus is to provide specialist, age-appropriate respite day care that supports every individual to achieve their maximum potential.

Method Consultation took place with all key stakeholders from health, education and social care to provide a homely social hub. Within this bespoke facility is also a wet room and specialist equipment to enable some of our young people, who do not have these facilities at home, to relax and bathe. Counselling rooms; play therapy room; a sensory room and a courtyard garden are also provided.

Conclusion Whilst developing this model of care, we reviewed our vision and mission statements to incorporate this new service. Alongside the transitional care service, the Young People's Hub also houses a Children's Bereavement Service and our Young Carers support group. Since its inception at the Shakespeare Hospice, we have received referrals from Warwickshire, Birmingham, Solihull, Worcestershire and Oxfordshire. Our unique model of care is well known within the West Midlands Region and our team have presented our journey in developing transitional care on many occasions at various events across the UK.

\section{P-216 ADULT AND CHILDREN'S PALLIATIVE CARE SERVICES WORKING TOGETHER TO TRANSFORM TRANSITIONS}

${ }^{1}$ Liz Smith, ${ }^{1}$ Fiona Wylie, ${ }^{2}$ Jayne Grant. ${ }^{1}$ The Prince and Princess of Wales Hospice, Glasgow, UK: ${ }^{2}$ Children's Hospices Across Scotland, UK

\subsection{6/bmjspcare-2017-hospice.241}

Background There is growing evidence of the increased number of young adults (YA) living with life-limiting conditions in Scotland (ChiSP Study, 2015), as well as evidence of their unmet needs and poorer outcomes (Care Quality Commission, 2014). As a result adult hospices have been challenged to acknowledge the role they have in supporting YA and their families (Together for Short Lives, 2013). To support the above transitions the Prince and Princess of Wales Hospice (PPWH) recognised the need to ensure their staff had the appropriate knowledge, skills and competence to support YA and their families. Recognising a gap in these areas the hospice sought potential support and collaboration with Children's Hospices Across Scotland (CHAS).

Aims

1. Develop and support hospice staff to deliver a high standard of care to YA and their families, identifying gaps requiring

further training and education
2. Establish relationships and trust between children and adult hospice services, YA and their families

3. To inform the development of the hospice service model.

Methods

- Provision of joint workshops to identify staff's anxieties and learning needs around YA care

- Development of 18 month seconded programme to CHAS open to all hospice staff

- Post-secondment evaluation informed by feedback from workbook; staff questionnaire, 1:1 and group reflection.

Results To date 13 clinical and non-clinical staff have taken part in the secondment programme.

- All staff have reported a greater understanding of the needs of YA with increased confidence and empowerment to meet these

- Greater relationship and trust with YA and their families resulting in increased referrals

- Greater opportunity to engage with YA and their families which has informed the development of the YA Service Model.

Conclusion This partnership working has been an effective way of influencing and managing change. Directly impacting on patient and family experience, staff skills and confidence and co-production of a service model.

\section{P-217 PAEDIATRIC PALLIATIVE CARE TRANSITION - A SERVICE EVALUATION OF SUPPORT FOR TEENAGERS WITH LIFE-LIMITING CONDITIONS IN SOUTH WALES}

${ }^{1}$ Rachel Watson, ${ }^{2}$ Timothy Warlow, ${ }^{3}$ Megumi Baba. 'University of Cardiff Medical School, Cardiff, UK; ${ }^{2}$ University Hospital of Wales, Cardiff, UK; ${ }^{3} T \hat{y}$ Hafan Children's Hospice, Sully, UK

10.1136/bmjspcare-2017-hospice.242

Background With the increasing survival of children with lifelimiting conditions, support through teenage years and into adult services is of vital importance to children and families. The All Wales Paediatric Palliative Care Team has identified the need to implement a robust transition service.

Aims Undertake a two stage service evaluation of transition support in South Wales:

1) An audit of current provision against national transition guidance from NICE (2016) and Together for Short Lives (2015)

2) A qualitative assessment of the transition process by staff and families.

Method A retrospective notes audit was completed using hospice and hospital records. Care provided for 20 patients of transition age (14-17 years), and 10 patients post transition $(18+)$ was assessed. Semi-structured interviews were conducted with eight families and 17 staff working with transition patients in a variety of roles.

Results For $25 \%$ of families, transition was the main concern they had when considering their child's future. During transition planning, all families had their ethical and cultural needs considered, with family wishes/aspirations for adulthood recorded in $63 \%$ of cases. $13 \%$ had documented goals for transition. There was no documented support for developing identity/sexuality/relationships, or spiritual development. By transition age, $37 \%$ had their needs met by an appropriate adult service. Two-thirds of families felt well supported during their transition. $67 \%$ felt poorly informed regarding adult 
services, despite $80 \%$ having met a member of adult palliative care team. No patients had a formal transition plan. $50 \%$ of staff felt support for transition was inadequate, with $70 \%$ expressing the need for improved continuity in the service.

Conclusion A clear transition process is required to ensure early planning, that needs are met by adult services, and that family goals drive the transition process. Issues of identity, sexuality and spiritual development require specific focus. Funding, training and improved key working need to be addressed. A multidisciplinary approach with improved access to adult respite services is vital.

\section{P-218 MODEL OF CARE: A STRUCTURE AND PHILOSOPHY THAT EMPOWERS, ENABLES, EQUIPS ADULTS AND THEIR FAMILIES}

Ray Wilson, Mark Jarman- Howe, Laura Shukla. St Helena Hospice, Colchester, UK

\subsection{6/bmjspcare-2017-hospice.243}

Background Responding to stakeholder feedback and wider strategic developments, led us to review how we deliver care to be more social and personalised. Growing demand affected staff's ability to work in a structured way leading to unmet expectations.

Aims We adjusted our approach to multidisciplinary team assessments with the following aims for patients and families:

- To have an initial holistic assessment, using a SystmOne core template, by an appropriate hospice professional, not necessarily a nurse specialist

- Their goals are identified, with a view to achieving results within six sessions.

This new model's aims are to enable, equip and empower people by:

- Maximising their existing support network

- Sourcing alternative/additional support

- Providing hospice support (six sessions of care model) 'sticking like glue' to ensure issues are identified, goals set and a plan agreed.

Method A cross-organisation project group reviewed referral criteria and assessment processes. SystmOne templates were revised and the Outcome Assessment and Complexity Collaborative, Adult Social Care Outcomes Framework and Essex County Council's '3-conversation model' embedded in a core assessment. Staff were reorganised to enable a more responsive service.

Results Early indications are that this will achieve:

- Common understanding for hospice staff by working within one structure

- More comprehensive, timely crisis response - 'right person, right skills, right place, right time'

- Multi-disciplinary teams using their skills from first holistic assessment - 'right person, right skills, right place, right time'

- Widening access to the hospice

- Integrated health and social care assessment, adhering to Care Act 2014

- Measurable outcomes

- Model potentially to be replicated across the local health system

- All stakeholders clearer about what we offer.
Conclusion This model of care provides a clear structure for hospice professionals, empowers patients and families, ensures greater access to hospice care, responds to patient and family needs in a person-centred and timely way and provides evidence of outcomes and impact.

\section{P-219 THE EARLIER THE BETTER: EARLY REFERRAL TO PALLIATIVE CARE IMPROVES QUALITY OF LIFE}

Sue Eskins, Becky Avery, Lynn Porch, Sarah Parkes. Dorothy House Hospice Care, Wiltshire, UK

\subsection{6/bmjspcare-2017-hospice.244}

Background In 2014 the WHO declared that 'early palliative care not only improves quality of life for patients but also reduces unnecessary hospitalisation and use of health care services'. Following an audit in 2014 the Contact Centre at our hospice were aware that there were a number of patients who would benefit from our services but were either declining the services or being declined due to not being able to meet the criteria for specialist palliative care and end of life care.

Aims To develop an early palliative care service which allowed the patients and families/carers to experience a modern hospice approach of living well and palliative reablement. This included:

- Advance care planning

- Early support for families and carers

- Networking with other agencies e.g., CAB, carers support

- Live well approach

- Opportunity for referral to hospice services to prevent crisis e.g., 24 hour advice line, $\mathrm{H} @ \mathrm{H}$

- Psychological support.

Methods

- Outpatient style appointment at an Outreach Centre close to home at the patient's/family convenience with a named nurse.

- Patient centred approach

- Referral to other internal and services

- Flexible approach to use of hospice services.

Results

- Significant increase in the number of patients/families gaining access to hospice services

- Extension of lighter touch services

- Increase in referrals of non-cancer and long term conditions

- Positive feedback from patients/families

- Earlier referral for some patients to complex specialist services

- Development of the nursing team's skill mix

- De-stigmatises hospice care.

Conclusion

- Further investment in the early referral services as patients and families/carers are utilising living well and palliative reablement services

- An opportunity to encourage end of life conversations and advance care planning for patients with dementia

- Potential to extend into GP surgeries/satellite clinics to reduce anxiety around being referred to a hospice

- Potential to extend into outpatient services at local hospitals to support patients who are newly diagnosed as palliative. 